\title{
Precursors to melanoma and their mimics: nevi of special sites
}

\author{
David E Elder \\ Department of Pathology and Laboratory Medicine, University of Pennsylvania Health System, Philadelphia, \\ $P A, U S A$
}

\begin{abstract}
Melanocytic nevi, which are benign tumors of melanocytes, may have occasional cosmetic significance but, for the most part, they are important only in relation to melanoma. Nevi are the most important simulants of melanoma, both clinically and histologically, and can usually be reliably distinguished from melanomas using published criteria. Some lesions are characterized by greater degrees of atypia and may be more difficult to diagnose. Dysplastic nevi are among the most important simulants of melanoma. Nevi may also be important as potential precursors of melanoma; however, most nevi are stable and will not progress to malignancy. Nevi are vastly more common than melanomas and the rate of progression of individual lesions is very low. Therefore, nevi are not as a rule managed by wholesale excision to prevent melanoma. Nevi are also important as risk markers, identifying individuals at greater risk of developing melanoma in the future. Dysplastic nevi and, to a lesser extent, common acquired and congenital nevi are among the most important melanoma risk markers. Nevi of special sites have been identified as nevi that may show atypical features suggestive of a dysplastic nevus or of a melanoma. However, they are not risk markers and they are not malignancies. Nevi of genital skin, acral skin, and flexural skin are among the most important 'nevi of special sites'. It is important, in considering the differential diagnosis of a lesion in a special site, to avoid overcalling such a lesion as a melanoma or a dysplastic nevus because this could lead to excessive treatment. Conversely, it is important to avoid undercalling a lesion that is a dysplastic nevus or a melanoma as a nevus of special sites, because in this circumstance a patient could lose the opportunity either for surveillance to recognize a developing melanoma at an early, curable stage, or for definitive treatment of an established malignancy. In this monograph, dysplastic nevi and nevi of special sites are compared and contrasted in relation to melanoma.

Modern Pathology (2006) 19, S4-S20. doi:10.1038/modpathol.3800515
\end{abstract}

Keywords: melanocytic nevi; nevi of special sites; genital nevi; acral nevi; dysplastic nevi; malignant melanoma

Melanocytic nevi are benign tumors of melanocytes. Except for occasional cosmetic significance, for the most part, nevi are important only in relation to melanoma. As such, they may have significance as either simulants of melanoma, as markers of individuals at increased risk for melanoma, or as potential precursors for melanoma. Dysplastic nevi are the most important simulants, risk markers, and potential precursors of melanoma. Congenital melanocytic nevi have similar but more limited significance, and the largest of these also have cosmetic significance. Common acquired nevi are also potential simulants, as well as being weak risk markers and potential precursors of melanoma. The degree of atypia exhibited by congenital and common ac-

Correspondence: Dr DE Elder, MD, ChB, FRCPA, Department of Pathology and Laboratory Medicine, University of Pennsylvania Health System, 3400 Spruce Street, Philadelphia, PA 19104, USA. E-mail: elder@mail:med.upenn.edu

Received 23 September 2005; accepted 28 September 2005 quired nevi is much less than that in dysplastic nevi, both clinically and histologically. Therefore, with rare exceptions such as the need to distinguish a benign nevus from a nevoid melanoma or a nevoid metastatic melanoma, common acquired nevi do not usually present diagnostic problems as melanoma simulants. Nevi of special sites have been identified as lesions that may simulate dysplastic nevi on the one hand, or melanomas on the other hand. This review will consider the significance of dysplastic nevi and of special site nevi.

\section{Dysplastic nevi}

Dysplastic nevi present atypical features both clinically and histologically, and thus are important as simulants of melanoma. ${ }^{1-7}$ Clinically, they are characterized by four major properties (Figure 1): Their size tends to be greater than that of common nevi but less than that of melanomas; in the most 


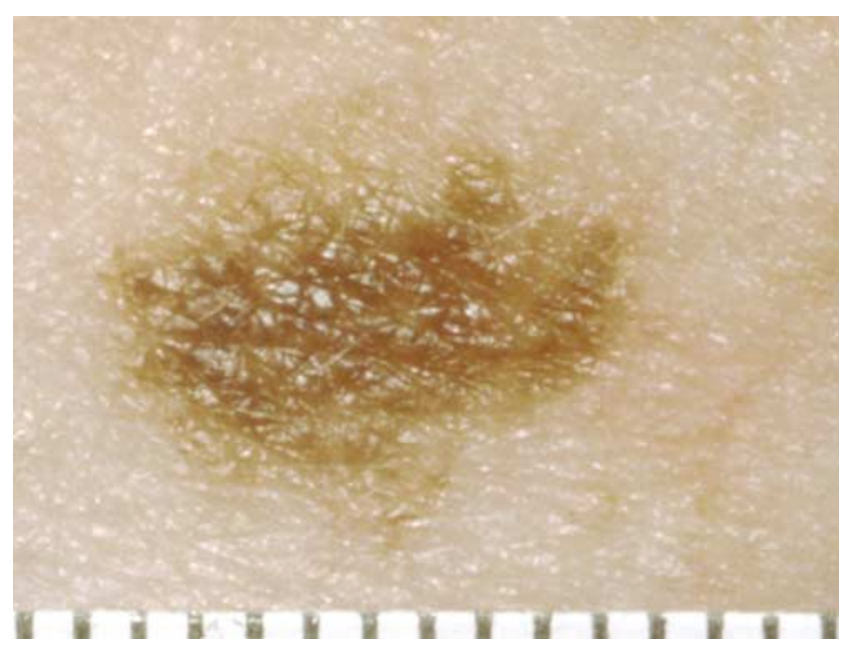

Figure 1 Dysplastic nevus, clinical. The lesion is broader than $5 \mathrm{~mm}$, within a regular border that is indefinite or 'fuzzy' in some areas, and with slightly variegated shades of tan and brown pigment.

common definition, dysplastic nevi are $5 \mathrm{~mm}$ in diameter or greater. Also by definition, dysplastic nevi contain a junctional component, which clinically is macular or flat, sometimes with a 'pebbly' surface. The border of this junctional component tends to be ill defined or 'fuzzy', compared to that of a papular compound nevus or even of a superficial spreading melanoma, which tends to have a sharp discrete border. Finally, dysplastic nevi exhibit pigmentary variegation. Shades of tan and brown tend to predominate, in addition to reddish colors. Darker blue-black colors are more usually seen in melanomas and should elicit biopsy. These features have been recently illustrated in an atlas. ${ }^{8}$ Dysplastic nevi overlap clinically with the widely used ABCDE criteria for melanoma, ${ }^{9,10}$ in which the letters stand for Asymmetry, Border irregularity, Color variegation, Diameter $>6 \mathrm{~mm}$, and Enlargement or Evolution. However the changes in dysplastic nevi are present in lesser degree. In serial photographic follow-up, dysplastic nevi are stable or may even regress. Thus, they do not display the (E) phenomenon of 'Enlargement', or increase in size, nor do they exhibit other sinister changes such as increase in elevation, development of a nodule, bleeding, or ulceration. In a recent study, observers tended to use a 'gestalt' of findings, rather than these individual findings taken separately. The so-called 'ugly duckling' sign of a lesion that looks different from other nevi on the patient's skin is often the motivation for recognition of a melanoma, whether it be by patients, their relatives or friends, or by physicians. $^{11}$

The importance of dysplastic nevi as precursors of melanoma is tempered by the fact that only a small percentage of these lesions will progress, typically visualized as the focal evolution of a melanoma within a pre-existing dysplastic nevus. This phe-
Table 1 Relative risk of melanoma in patients with common versus dysplastic nevi (Tucker et $a l^{28}$ )

\begin{tabular}{lccr}
\hline \multicolumn{2}{c}{ Common nevi } & \multicolumn{2}{c}{ Dysplastic nevi } \\
\hline \# of nevi & $R R$ & \# of nevi & $R R$ \\
\hline $0-24$ & 1.0 & 0 & 1.0 \\
$25-49$ & 1.8 & 1 & 2.3 \\
$50-99$ & 3.0 & $2-4$ & 7.3 \\
$100+$ & 3.4 & $5-9$ & 4.9 \\
& & $10+$ & 12.0 \\
\hline
\end{tabular}

nomenon is occasionally recognized clinically in surveillance photographs. ${ }^{8}$ However, the best evidence for this association is the histological recognition of dysplastic nevi in contiguity with a melanoma, which is observed in about $20-40 \%$ of cases in most studies. ${ }^{12-17}$ Thus, the majority of melanomas do not arise in association with a demonstrable nevus. The prevalence of dysplastic nevi is vastly greater in populations than that of melanoma, indicating, consistent with clinical observations, ${ }^{18}$ that most dysplastic nevi are stable and do not progress to melanoma. Thus, there is no justification for the wholesale excision of dysplastic nevi in an effort to prevent melanoma.

Although the concept of dysplastic nevi has been controversial, there is widespread agreement about the significance of clinically dysplastic nevi, which are also known as 'clinically atypical nevi', 'atypical nevi', or 'atypical moles', as markers of individuals at increased risk for melanoma. This risk has been demonstrated in case-control studies and in cohort studies. In the latter, groups of patients with clinically dysplastic nevi have been followed clinically and a markedly increased incidence of melanoma has been documented. ${ }^{19-21}$ In case-control studies, which compare the prevalence of risk factors between cases and controls from a defined population, ${ }^{22-29}$ the relative risk for melanoma of individuals with these factors can be estimated. The single best study of clinically dysplastic nevi is that of Tucker et al. ${ }^{28}$ This was a case-control study done in two sites, San Francisco and Philadelphia. In this and in all other similar case-control studies, ${ }^{22-29}$ the number of nevi and the number and prevalence of dysplastic nevi is greater in the cases than in the controls. From this observation, the relative risk for developing melanoma in patients with increased nevi or dysplastic nevi can be calculated and is presented in Table 1.

As shown in the table, individuals with 100 or more common acquired nevi have a 3.4-fold increased risk for melanoma, while individuals with 10 or more dysplastic nevi have a 12-fold excess risk for melanoma. Therefore, lesion for lesion, dysplastic nevi are more powerful risk markers than common nevi. Patients with more than 10 dysplastic nevi are rarely found in communities, and thus are 
uncommon in controls. However, in specialized pigmented lesion clinics, patients with many more than this number of dysplastic nevi are not uncommonly encountered, and the risk may be expected to be increased commensurately. Other risk factors for melanoma that have been reported in various case-control studies include phenotypic factors (such as blue eyes, blond or red hair, light complexion, freckles, sun sensitivity, and inability to tan); personal history of nonmelanoma cutaneous cancer or precancer; higher socioeconomic status; increased numbers of nevocytic nevi; and bursts of sun exposure, nevus size, and a family or personal history of melanoma. ${ }^{25,28,30,31}$ Patients with combinations of these factors may have extraordinarily high risks of melanoma. Halpern et $a{ }^{18}$ presented data from a cohort study in a pigmented lesion clinic to indicate that the risk for melanoma may be increased more than a 1000-fold in individuals who have the combination of dysplastic nevi on their skin with a family and personal history of melanoma. Mackie et $a l^{32}$ presented a 'risk factor chart' for a Scottish population, which demonstrates the interactions among several risk factors (total number of benign pigmented nevi above $2 \mathrm{~mm}$ diameter, freckling tendency, number of clinically atypical nevi, and a history of severe sunburn at any time in life) quite well.

Histologically, dysplastic nevi are characterized by two major categories of criteria: architectural and cytologic $^{1,3,3-6,33}$ (Figures 2 and 3). Architecturally, just as is true by definition clinically, dysplastic nevi are larger than common acquired nevi and the diagnosis should be made cautiously in lesions smaller than about $4 \mathrm{~mm}$ in diameter on the slide. Also by definition, dysplastic nevi contain a junctional component, which is commonly present as a 'shoulder', adjacent to a compound papular 'head'. In other lesions that lack a dermal component, the lesion is entirely junctional. Especially within the junctional component, there is an increased number of single and nested melanocytes arranged with nests predominating, predominantly near the tips and the sides of elongated rete ridges, with some nests bridging between adjacent rete. The rete ridges tend to be uniformly and irregularly elongated in dysplastic nevi, in contrast to melanomas, in which there may be atrophy or irregular hyperplasia of the epidermis with a tendency to effacement of the rete in either case. In the dermis, there is fibroplasia, typically in the form of concentric eosinophilic fibroplasia or lamellar fibroplasia. Diffuse fibroplasia, often associated with a band-like lymphocytic infiltrate, is more commonly seen in melanomas. Cytologically, a minority of the cells in dysplastic nevi exhibit atypia, termed 'random' cytologic atypia. Atypia, as in other systems, is characterized by nuclear enlargement, slight irregularity, and hyperchromasia, with clumping of chromatin and sometimes with prominent nucleoli. These criteria differ from those of the lesion that has been termed

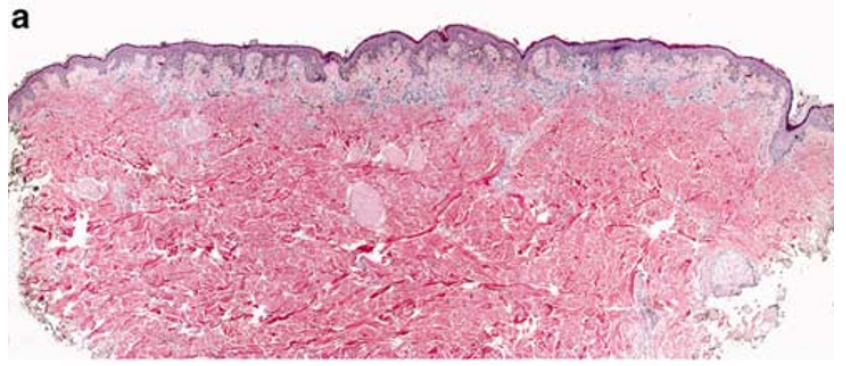

b
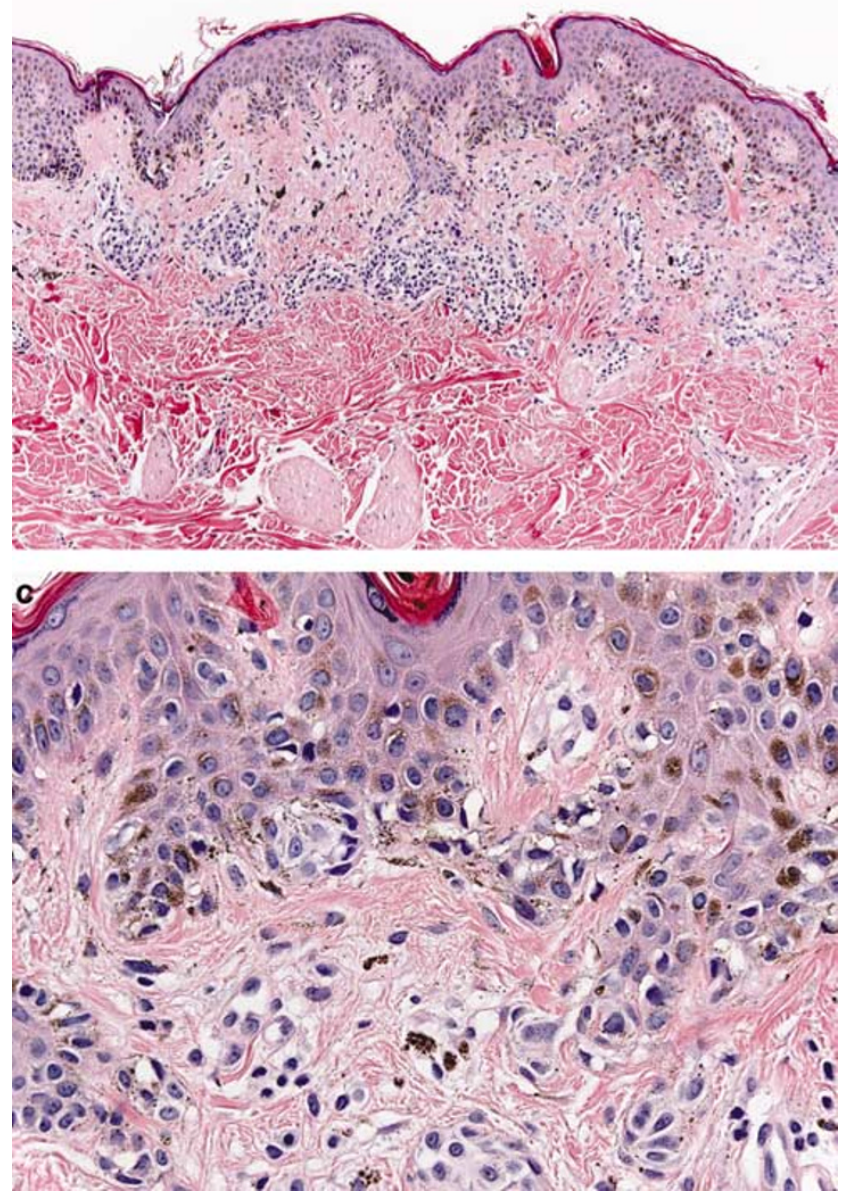

Figure 2 Dysplastic nevus, with mild architectural and cytologic atypia. At scanning magnification, the lesion is broader than 4$5 \mathrm{~mm}$, and is confined to the epidermis and the papillary dermis (a). Architecturally, the lesion is comprised of predominantly nested melanocytes, arranged predominantly near the dermalepidermal junction near the tips and sides of elongated rete ridges, with some nests bridging between adjacent rete (b). Cytologically, there is mild to moderate enlargement and hyperchromatism, and slight irregularity of scattered lesional cell nuclei, with a few nucleolated lesional cells (c).

'Clark's nevus', in which size and cytologic atypia are not considered. ${ }^{34,35}$ These histologic features of dysplastic nevi overlap, to some extent, with common nevi on the one hand, especially small lentiginous compound or junctional nevi, and with early melanomas on the other hand. Nevertheless, most studies, ${ }^{6,36-44}$ but not all, ${ }^{45}$ have found accep- 


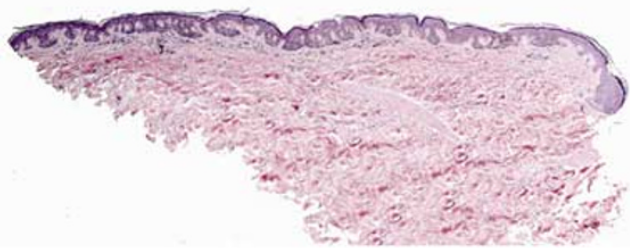

b

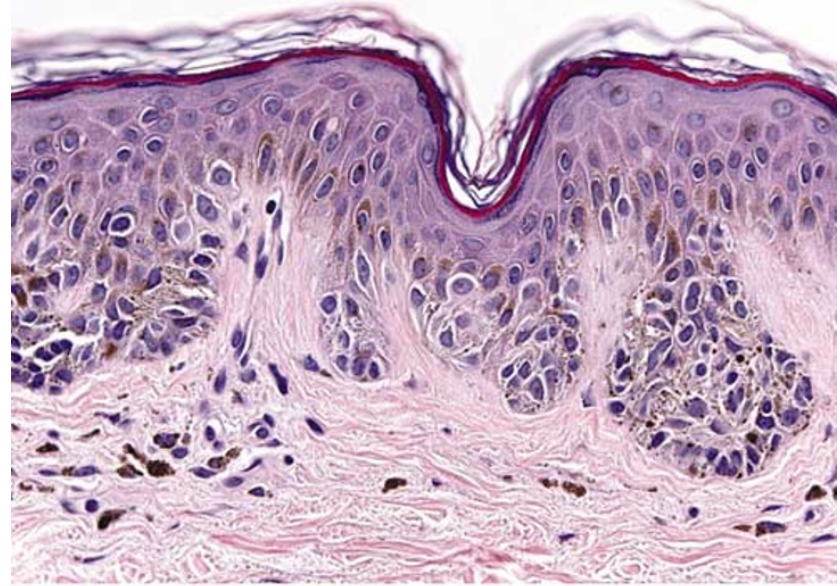

c

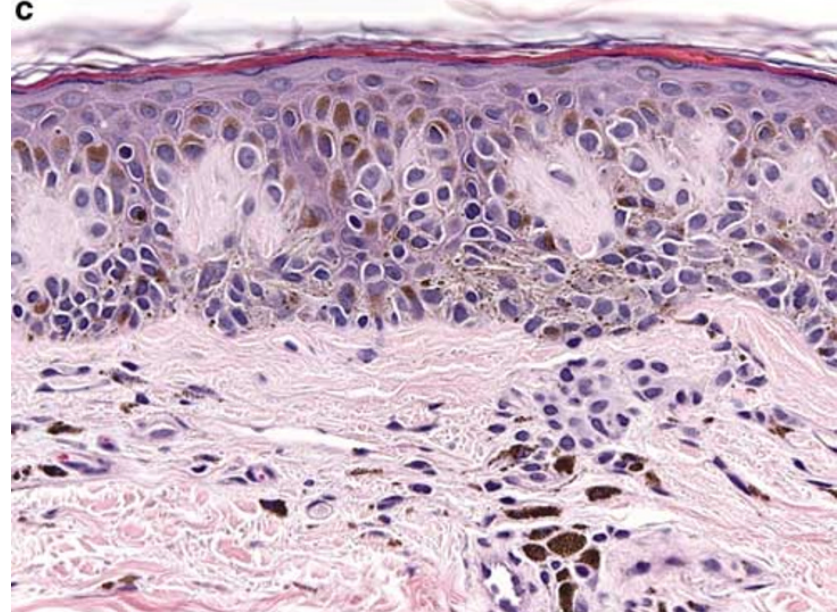

Figure 3 Dysplastic nevus, with moderate to severe architectural and cytologic atypia. At scanning magnification, the lesion is broader than $4-5 \mathrm{~mm}$ and confined to the epidermis and the papillary dermis (a). Higher magnification reveals enlarged melanocytes with prominent nucleoli arranged mainly in nests, mainly near the dermal-epidermal junction (b). In addition, there are a few single cells, with a suggestion of continuous proliferation in some areas of the lesion (c). This lesion was located on the breast of a 49-year-old female, who was a member of a hereditary melanoma kindred and had melanoma in situ elsewhere on her skin (illustrated in Figure 4).

table reproducibility, especially when there has been prior agreement upon criteria. In one multiobserver, population-based analysis of histologic dysplasia in melanocytic nevi, in which there was no prior agreement on criteria, it was concluded that 'although experienced dermatopathologists use different diagnostic criteria for histologic dysplasia, a

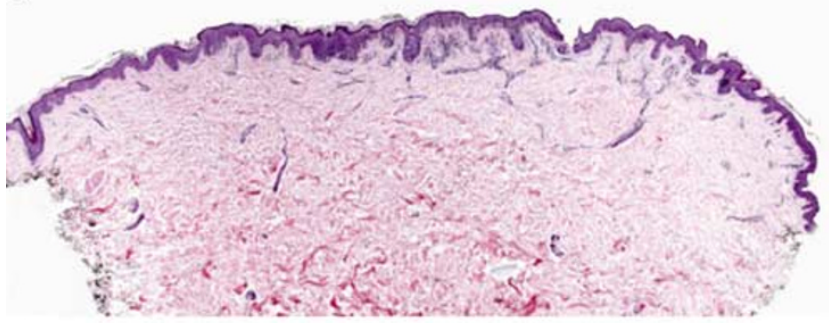

b
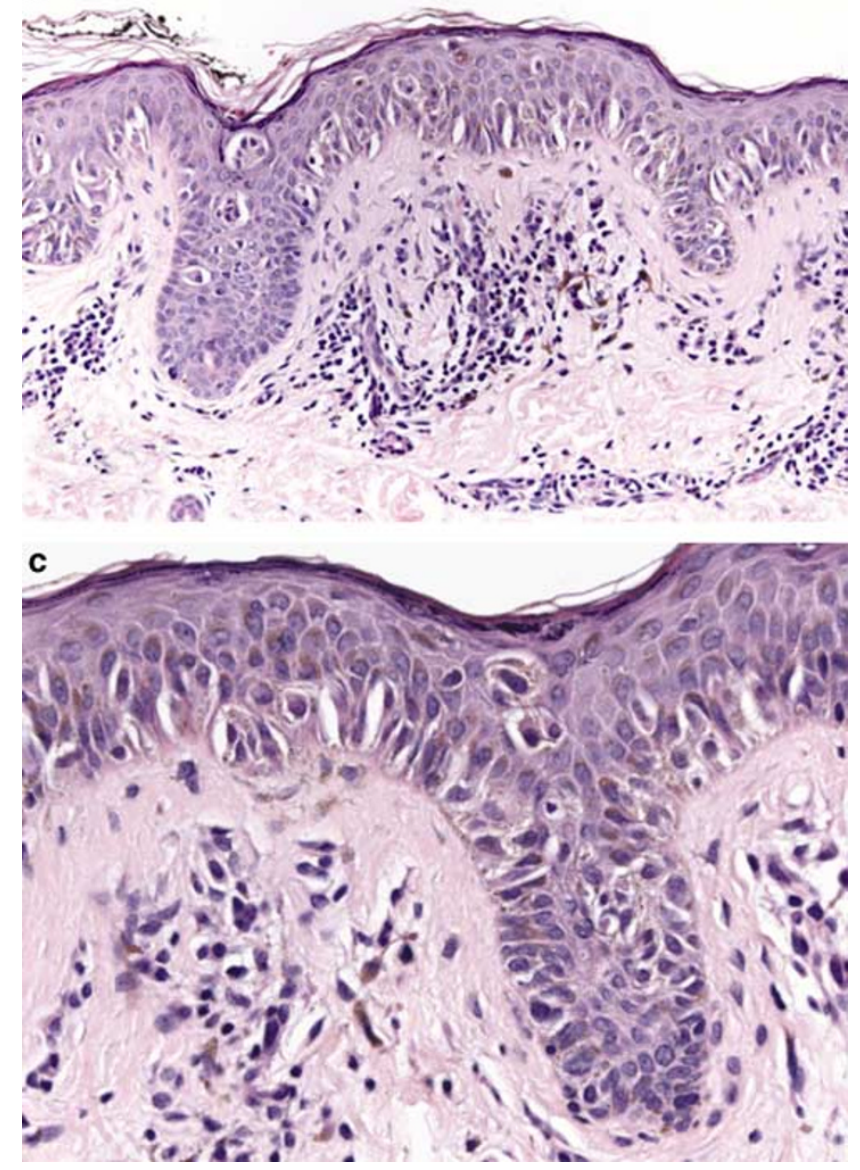

Figure 4 Melanoma in situ. Same patient as in Figure 3. Although smaller than $4 \mathrm{~mm}$ in diameter, the lesion is characterized by an increased number of single cells visible at scanning magnification, and by irregular thickening and thinning of the epidermis in contrast to the more uniform rete ridge elongation of dysplastic nevi (a). Higher magnification reveals 'buckshot scatter' of large epithelioid melanocytes, which exhibit uniform though generally moderate cytologic atypia. This pagetoid pattern of proliferation is both 'extensive' and 'high-level' in this lesion (b). High magnification reveals generally moderate but relatively uniform cytologic atypia in this in situ melanoma (c).

their usage is consistent', ${ }^{46}$ Thus, substantial to excellent reproducibility can be expected when consistent criteria are used. ${ }^{43}$

Criteria for the distinction among common nevi, dysplastic nevi (Figures 2 and 3), and nontumorigenic (radial growth phase) melanoma (Figure 4) are summarized in Table 2. These features begin with 
Table 2 Comparative features of nontumorigenic melanoma, dysplastic nevi, and common nevi

\begin{tabular}{|c|c|c|c|}
\hline Feature & Melanoma & Dysplastic Nevus & Nevus \\
\hline \multicolumn{4}{|l|}{ General } \\
\hline Size & Larger & Intermediate & Smaller \\
\hline Symmetry & Poor & Good & Good \\
\hline \multicolumn{4}{|c|}{ Architectural patterns } \\
\hline Nested & Variable & Predominant & Predominant \\
\hline Nests & Coalescent & Bridging & Discrete \\
\hline Lentiginous & Continuous & Discontinuous & Discontinuous \\
\hline Pagetoid & High, extensive & Low, focal, minimal & Minimal \\
\hline Rete ridges & Irregular & Uniformly elongated & Uniform \\
\hline \multicolumn{4}{|l|}{ Cytology } \\
\hline Melanocytes & Epithelioid & Mixed & Nevoid \\
\hline Nuclear atypia & Uniform atypia, & Random atypia & Minimal \\
\hline & & Moderate-severe & Mild-moderate \\
\hline Mitoses & About $1 / 3$ of cases & Almost always absent & Absent \\
\hline \multicolumn{4}{|l|}{ Stromal responses } \\
\hline Fibroplasia & Diffuse & Concentric & Minimal \\
\hline Lymphocytes & Band-like, lichenoid & Patchy, perivascular & Minimal \\
\hline Regression & Frequent, extensive & Rare, minimal & Absent \\
\hline
\end{tabular}

the overall features of size and symmetry visible grossly and at scanning magnification. At low and medium power, the architectural features of interest include those of keratinocytes, melanocytes, and stromal cells including lymphocytes. The keratinocytes tend to show uniform elongation in nevi and dysplastic nevi, with irregular hyperplasia in melanomas. Melanocytes tend to be arranged as single cells in many early melanomas, with nests predominating in most nevi. When nests are present in melanomas, they tend to vary in size, shape, and orientation, whereas in dysplastic nevi, they tend to bridge adjacent rete. The 'lentiginous' or single cell pattern tends to be continuous between rete in melanomas, while being discontinuous in nevi (confined to the tips and sides of the rete while sparing the suprapapillary plate region). Pagetoid extension into the epidermis, when present, tends to be extensive and to a high level in melanomas, while minimal or absent in nevi. Nuclear atypia is moderate to severe in melanomas and 'uniform', tending to involve a majority of the cells, while being mild to moderate in dysplastic nevi and 'random', involving a minority of the cells. Stromal responses also are of value in diagnosis: the lymphocytic response tends to be band-like and lichenoid, in contrast to the patchy perivascular response in nevi, and the fibroblastic response tends to be diffuse in contrast to the concentric fibroplasia in dysplastic nevi. Cytologic atypia, and stromal responses, are minimal or absent in common nevi.

Histologically, dysplastic nevi, like clinically dysplastic nevi, have significance as risk markers for melanoma. This relationship was studied recently by Arumi-Uria et $a l^{7}$ at Cornell University. Using criteria similar to those discussed above, these observers found that the prevalence of a personal history of melanoma was increased in patients with 'nevi with architectural disorder (NAD)' and various grades of histologic atypia (dysplasia). ${ }^{7}$ The grading of atypia involved architectural and cytological features, which were often correlated. Architectural criteria included intraepidermal junctional extension beyond any dermal component, complex distortion of rete ridges, and dermal fibrosis. Cytological criteria were based on nuclear size, dispersion of chromatin, prominence of nucleoli, hyperchromasia, and variation in nuclear staining. The odds ratios, as a measure of association between NAD and personal history of melanoma, were 4.08 for NAD-severe vs NAD-mild, 2.81 for NAD-severe vs NAD-moderate, and 1.45 for NAD-moderate vs NAD-mild. These authors concluded that 'the risk of melanoma is greater for persons who tend to make nevi with high-grade histologic atypia'.

Taken together, these findings indicate that it is important to recognize individuals with dysplastic nevi. Melanoma risk is most conveniently estimated clinically, by estimating the number of total nevi and dysplastic nevi, assessing indicators of sun damage such as freckles and actinic elastosis, taking an environmental and family history, and taking into account any prior history of melanoma. Individuals with a combination of these risk factors may have more than a 1000-fold increased risk for subsequent melanomas. ${ }^{19}$ In addition, the Cornell studies have indicated that a histologic diagnosis of melanocytic atypia (dysplasia) is also associated with increased melanoma risk. For patients with severe atypia, the risk of melanoma was almost three-fold greater than for those patients with mild atypia. ${ }^{7}$ In the opinion of this author, a pathologist can contribute to the assessment of melanoma risk by identifying histologically dysplastic nevi or nevi with 'dysplastic features'. If these findings are recorded in a 
pathology report, the clinician should be alerted to assess the risk factors discussed above, and thus to identify individuals whose increased risk for melanoma may warrant lifelong surveillance. Individuals with only one or a few dysplastic nevi and without other risk factors may be followed less intensively, or may not need to be followed.

Just as dysplastic nevi may simulate melanomas, so in turn dysplastic nevi may be simulated by other types of nevi, which do not appear to have the same systemic significance as dysplastic nevi. In addition, these other types of nevi may simulate melanomas as well. Lesions that show overlapping features with both dysplastic nevi and common acquired nevi are not uncommon. These lesions may be junctional or may have a 'shoulder' extending beyond a small dermal component. However, they are small in size, low in cellularity, and lack substantial cytologic atypia (Figure 5). ${ }^{47-49}$ These lesions, in general, do not simulate melanoma. They may be termed 'lentiginous compound (or junctional) nevi', and if

\section{a}
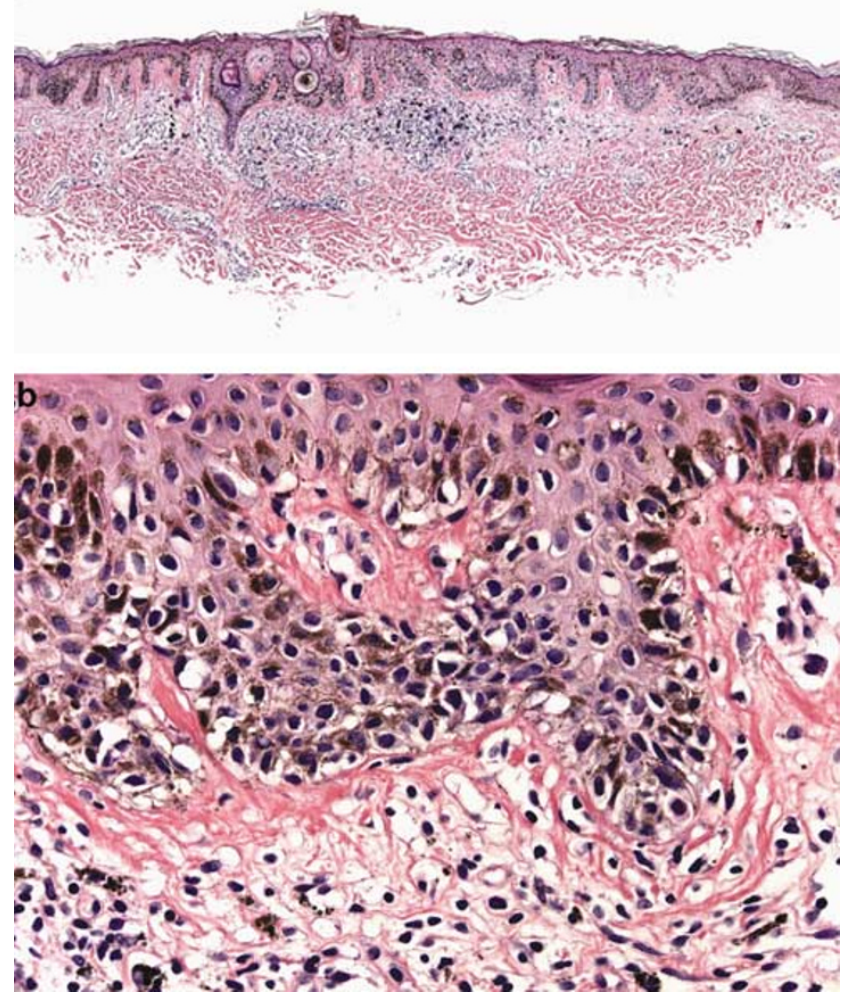

Figure 5 Lentiginous junctional nevus with 'dysplastic features'. At scanning magnification of this small lesion, there is rete ridge elongation, concentric fibroplasia, and a lymphohistiocytic infiltrate (a). At higher magnification, there is lentiginous proliferation of single cells among the dermal-epidermal junction, without cytologic atypia, and without continuous proliferation between the rete (b). Focally, there is a suggestion of continuous proliferation along the junction, an atypical architectural feature. Cytologic atypia is minimal. Although these changes may not be considered diagnostic of a dysplastic nevus, it would be appropriate to examine the patient for other clinically atypical nevi, especially if there is a family or personal history of melanoma. there is overlap with a mildly dysplastic nevus, this may be mentioned in a comment. For example, in such a circumstance, we might append a note as follows: 'This lesion has some features that may be associated with dysplastic nevi. Although this single lesion is not diagnostic, if this patient should have other clinically atypical nevi and especially if there is a family or personal history of melanoma, additional evaluation of melanoma risk factors and possible surveillance may be indicated'.

\section{Nevi of special sites}

A relatively common, recently recognized, and growing group of nevi may simulate both dysplastic nevi and melanomas. These lesions have been termed, generically, 'nevi of special sites'. These lesions may show architectural features overlapping with melanomas and may be overdiagnosed as such. If not interpreted as a melanoma, they may be classified as dysplastic nevi. However, many of these lesions appear to be isolated phenomena, not associated with measurably increased melanoma risk. At the same time, authentic dysplastic nevi may occur in these same 'special sites'. In the opinion of this author, it is just as important to recognize truly dysplastic nevi as such, as it is to avoid overdiagnosis of nevi of special sites as dysplastic nevi, or as melanomas.

Nevi on the skin of particular body sites and also in physiological states such as old or young age, or pregnancy may show patterns of junctional and/or dermal proliferation that may deviate from ordinary acquired nevi and cause confusion with atypical and dysplastic nevi, and with melanoma. In this review, the appearances of these 'special site' nevi will be described in nevi of genital, acral, and of flexural sites, and in nevi of the head and neck. Recognition of these appearances can help to avoid a mistaken diagnosis of a melanoma or a dysplastic nevus. In consideration of a diagnosis of a 'special site' nevus, however, the possibility that the lesion in question may be an authentic dysplastic nevus or a melanoma should always be given careful consideration. Difficulties of interpretation in these cases may result in some lesions from atypical or unusual features of the intraepidermal and superficial dermal components, or in other lesions from frankly tumorigenic proliferation of atypical melanocytes in the dermis.

Some lesions may be impossible to interpret with complete certainty, in which case a descriptive diagnosis may be all that can be rendered. For a problematical predominantly intraepidermal nontumorigenic and nonmitogenic proliferation (which may have a few cells in the dermis but does not show evidence of tumorigenic proliferation or mitotic activity there), we may use the descriptive term 'superficial atypical melanocytic proliferation of uncertain significance (SAMPUS). ${ }^{50}$ For lesions 
with a substantial dermal tumorigenic component, or with dermal mitoses, the term 'melanocytic tumor of uncertain malignant potential (MELTUMP) may be used. $^{50}$ Tumorigenic proliferation (vertical growth phase) in a melanoma is defined as the presence in the dermis of a cluster of cells that is larger than the largest cluster of cells in the epidermis. ${ }^{50,51}$

In a case where an 'uncertain potential' descriptive diagnosis is used, we typically offer a differential diagnosis. For example, we may favor an atypical nevus of the type seen on genital skin, but may not be able to rule out a melanoma. In that case, we believe that patient safety and appropriate management require that the clinician should be informed of the differential diagnosis of melanoma including its salient microstaging attributes, so that the management of the lesions can be discussed with the patient in an informed context. In most such cases, this will likely include an excision with (at a minimum) clear margins of normal tissue around the scar and any residual lesion, and for
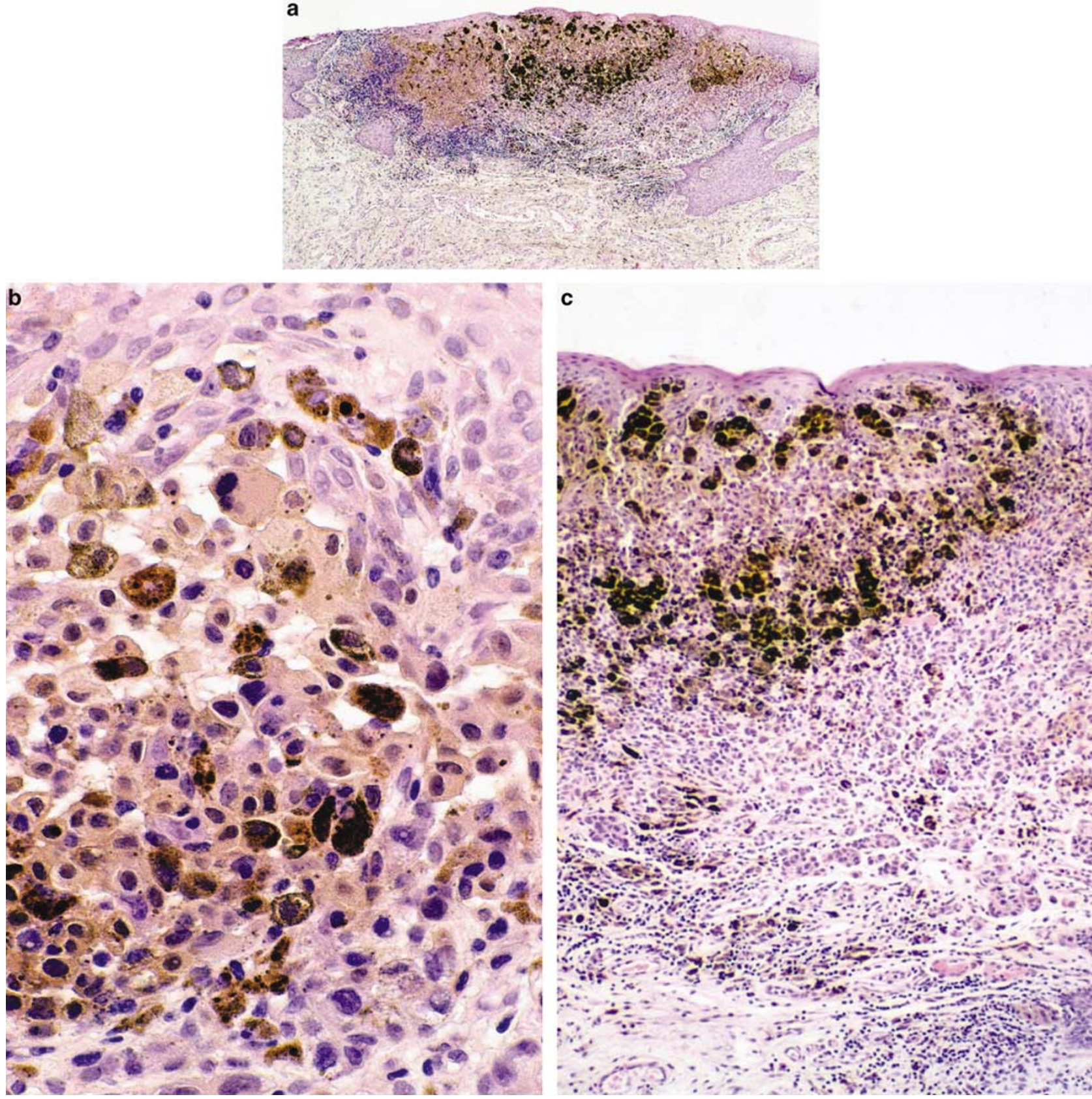

Figure 6 Genital pattern nevus. Despite its somewhat alarming cytology, this lesion is small, well circumscribed without an adjacent in situ component, and there is evidence of maturation from superficial to deep (a). The cells in the junctional component tend to be large and arranged in large nests, with dyshesion artefact (b). There is evidence of maturation from a larger cell type superficially, to a smaller cell type with less pigment toward the base of the lesion. There are no mitoses (c). 

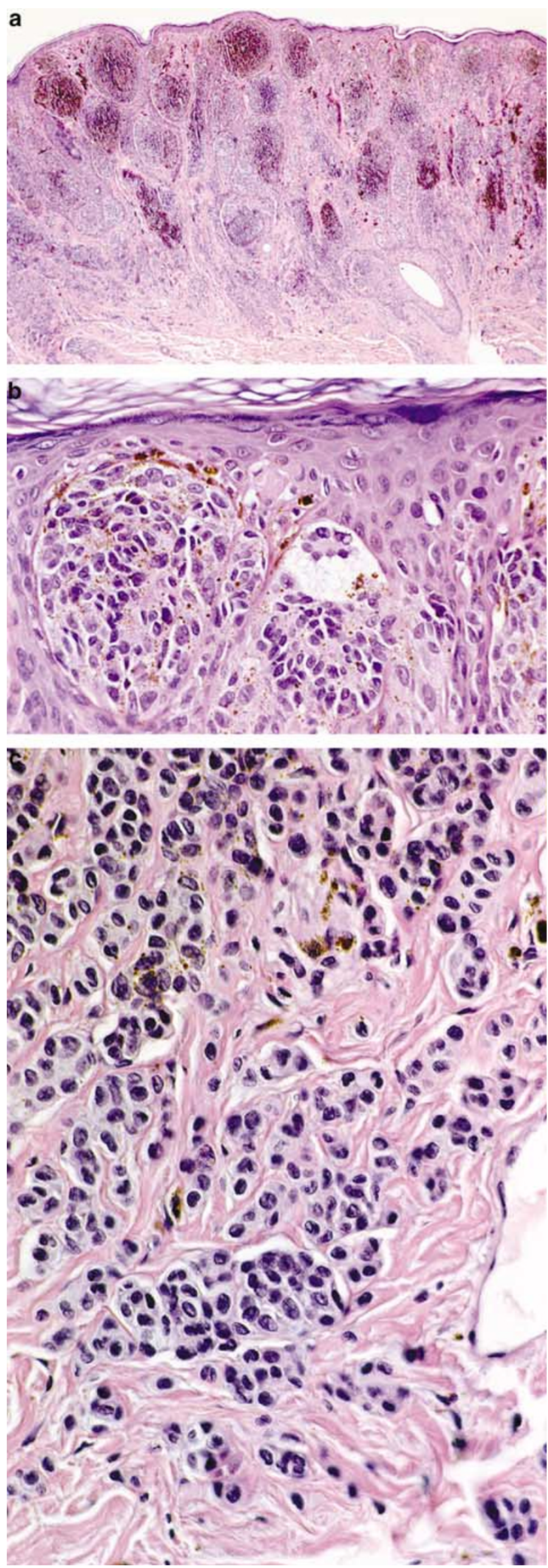

the tumorigenic MELTUMP lesions, a discussion of the pros and cons of sentinel lymph node sampling may be offered.

To summarize, the nevi of special sites may be simulants of both melanomas and of dysplastic nevi. Both underdiagnosis and overdiagnosis should be avoided. In particular, the existence of a 'special site' nevus diagnostic concept does not preclude the presence of authentic dysplastic nevi and melanomas on these same sites. Clearly, it is of paramount importance to recognize a melanoma wherever it may occur. In addition, patients with dysplastic nevi deserve to have these lesions recognized so that their risk factor status for a development of melanoma in the future may be assessed clinically and appropriate intervention may be considered. In some problematic lesions, a definitive diagnosis may be difficult or impossible to render. In such cases, we prefer a descriptive term, with a differential diagnosis.

\section{Nevus of genital skin}

\section{Definition}

These are benign melanocytic nevi that may present certain histologic features imperfectly simulating some aspects of dysplastic nevi and melanomas, including the presence of asymmetric patterns of growth, large cells, nucleoli, and a lymphocytic infiltrate. They are most often seen on the vulva of young (premenopausal) women, but similar lesions also occur uncommonly on the male genitalia. ${ }^{52-54}$

\section{Clinical Features}

The lesions are benign nevi that are often removed incidentally during pregnancy, often at the time of delivery. They are typically benign clinically, but certain histologic features may arouse a suspicion of melanoma on pathological examination. They are typically symmetrical papular lesions as viewed clinically, most often smaller than a centimeter in diameter, usually uniformly pigmented with discrete well-circumscribed borders. The histologically atypical changes are rare in vulvar nevi; in a comparative histologic study of vulvar nevi compared to controls, all but a few lesions were indistinguishable from control nevi of nonvulvar skin. In this study, biopsies of 85 pigmented vulvar lesions were studied. The nevi were compared to a

Figure 7 Genital pattern nevus. This lesion, from the vulva of a 28-year-old patient, did not have an adjacent in situ component. The lesional cells are large and are arranged in large nests, which tend to vary in size superficially (a). The large cells are arranged in large nests and there is dyshesion-the characteristic 'nested and dyshesive' pattern (b). The cells at the base are smaller and disperse as single cells into the reticular dermis collagen in a 'congenital pattern' (c). 
control series of 200 nevi from the torsos of women 20-60 years old. Three vulvar nevi in women between the ages of 20 and 30 years were considered to be unusual, but not dysplastic. The lesions exhibited notable enlargement of junctional melanocytic nests with variability in the size, shape, and position of the nests. Similar changes were not observed in the control group. There was no evidence of an increased incidence of vulvar dysplastic nevi when compared with the control series. $^{52}$

Vulvar nevi themselves are quite uncommon; in a recent study of 301 new patients in a gynecology practice, the prevalence of melanocytic nevi on vulvar skin was only $2.3 \% .^{55}$ The atypical features appear to represent a histologic curiosity seen in a minority of vulvar nevi, with no clinical significance except the possibility of diagnostic error. In our consultation practices, we have seen tragic examples of errors that have been followed by unnecessary ablative surgery in young women. Occasionally, we have observed these lesions in women who have characteristic dysplastic nevi elsewhere on their skin, but we do not regard these genital nevi as indicative, in themselves, of any generalized cutaneous diathesis. In other cases, authentic dysplastic nevi and melanomas have been observed in vulvar skin. Melanomas are more likely to occur in postmenopausal women, but we have observed fatal melanoma in young women as well. If an incompletely excised lesion presents atypical features similar to those described in this section, it is prudent to recommend complete excision so that the whole lesion can be examined to rule out additional pathology and to prevent persistence followed by recurrence, but formal 'wide' excisions of any kind are not indicated for these benign simulants of dysplastic nevi and of malignant melanoma.

\section{Microscopic Features}

The scanning magnification impression is typically that of a relatively small, well-circumscribed papular lesion composed of nevus cells arranged in clusters in the papillary dermis, and arranged mainly in nests in the epidermis where the cells do not extend beyond the shoulder of the dermal component (Figures 6 and 7). The nests tend to be large and variable in size, shape, and position, originating from the sides as well as the tips of rete, often oriented parallel to the surface, and may tend to become confluent Figure 4). Single cells and nests of nevus cells may occasionally be seen within the epithelia of skin adnexa, ${ }^{56}$ a feature shared with congenital nevi. The epidermis may show markedly irregular thickening, resulting in an impression of asymmetrical nevus cell proliferation. The keratinocytic proliferation differs from the lentiginous elongation of rete ridges seen in dysplastic nevi because it is less regular. Cytologically, cells forming these atypical nevi of genital skin are larger than nevus cells occurring elsewhere, particularly within the superficial component where they may also show eosinophilic nuclei. However, the lesions do not reveal mitotic activity, or individual cell necrosis, and generally the lesional cells demonstrate maturation with descent into the deeper dermal layers. Genital lentigines and nevi with concurrent changes of lichen sclerosus may show a lichenoid lymphocytic infiltrate and pigment incontinence with melanophages in a fibrosed papillary dermis, reminiscent of completely or partially regressed melanoma. Confluent nests varying in size and shape and with pagetoid upward spread of melanocytic nests and single melanocytes have been described in a few nevi associated with lichen sclerosus. ${ }^{57}$ These have been likened to persistent (or 'recurrent') melanocytic nevi. ${ }^{58}$

Table 3 Features helpful in differentiating compound nevi of genital skin from vulvar elanoma

\begin{tabular}{lll}
\hline & Nevus of genital skin & Vulvar melanoma \\
\hline Architecture & & \\
Size & Smaller $(<1 \mathrm{~cm})$ & Tend to be larger \\
Shoulder in adjacent epidermis & Absent & Often present \\
Lentiginous epidermal component & Absent & Often present \\
Pagetoid proliferation & Absent & Occasionally present \\
Coalescent junctional nests & Present & Occasionally present \\
Irregular junctional nests & Present & Occasionally present \\
Asymmetrical keratinocyte proliferation & Present & Variable to absent \\
Asymmetrical junctional component & Absent & Present \\
Asymmetrical dermal component & Absent & Often present \\
Cytology & & \\
Enlarged cells & Present superficially & \\
Eosinophilic nucleoli & May be present & Present diffusely \\
Maturation & Present & Present \\
Mitoses & Absent & Generally absent \\
Necrosis & Absent & Often present \\
\hline
\end{tabular}


Some of the features seen in atypical vulvar nevi, especially the large cell type in the epidermis and superficial dermis, may arouse suspicion of mela- noma. However, the lesions are comparatively small and well circumscribed, without extensive radial growth phase proliferation of atypical melanocytes a
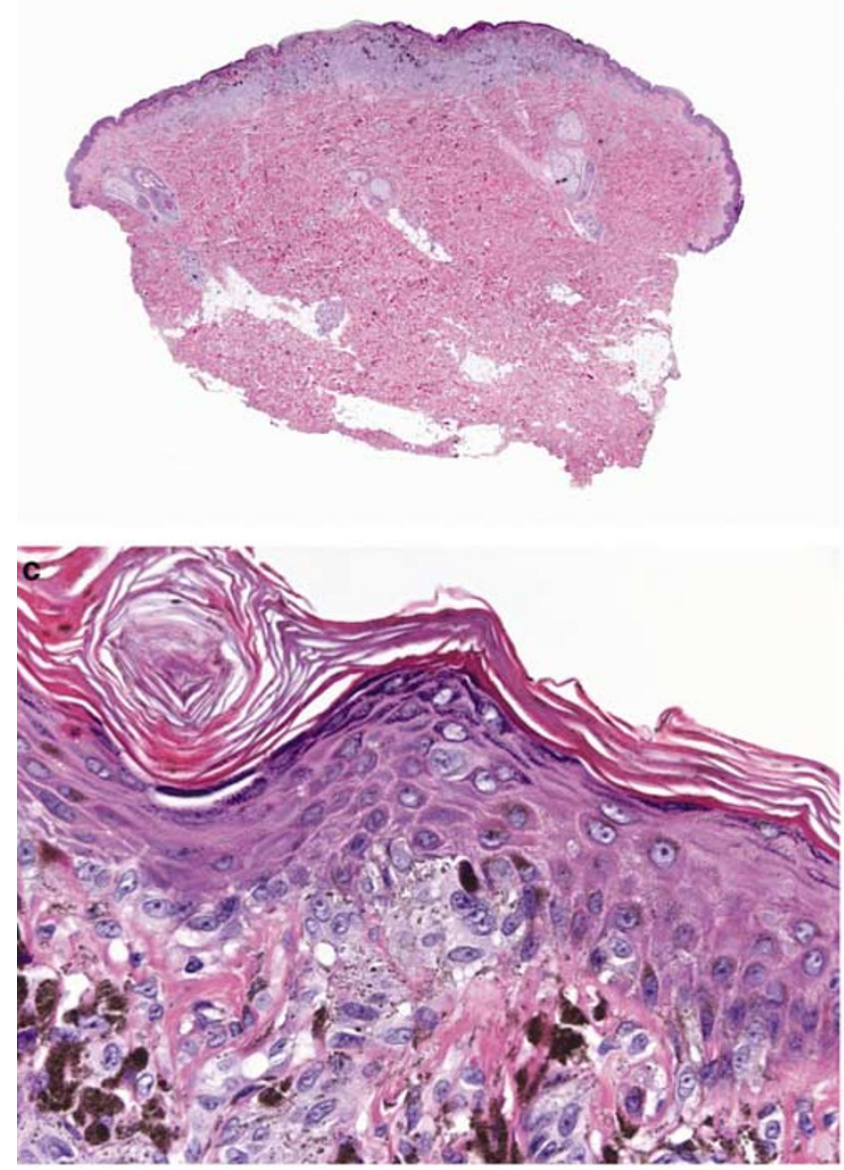

b

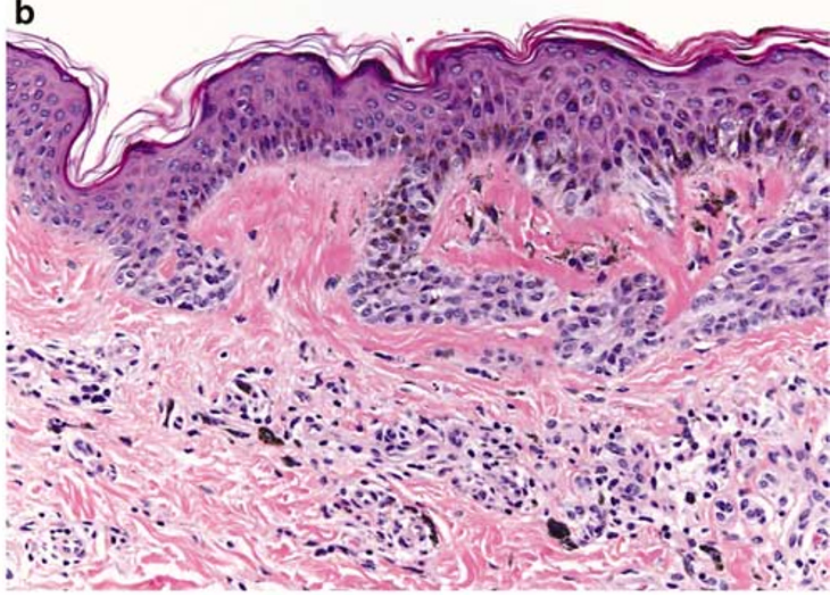

d

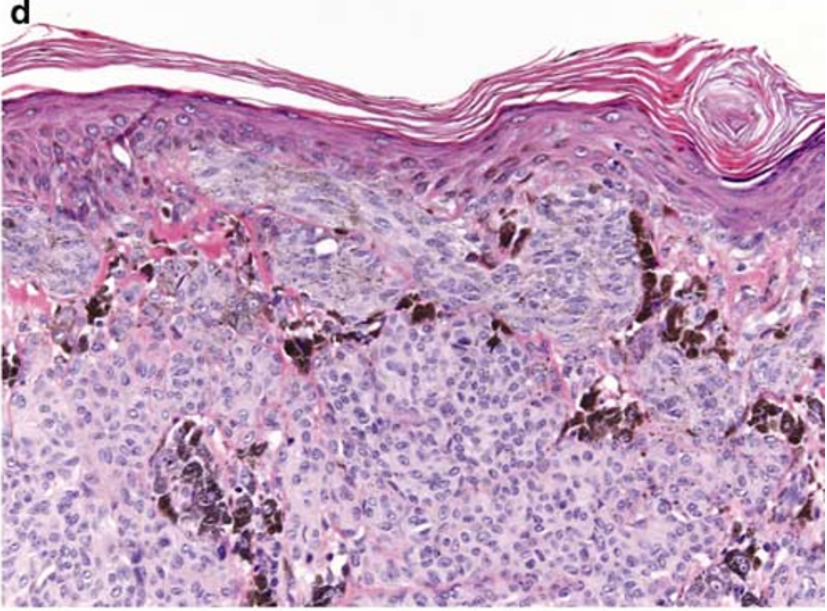

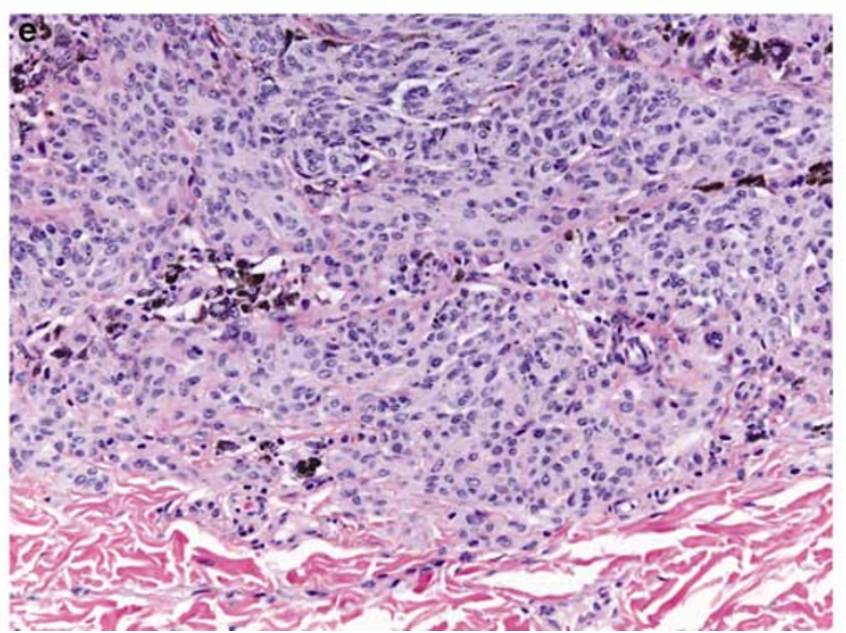

Figure 8 Unusual nevus of the breast in an 11-year-old patient. The lesion is quite broad and has a substantial dermal component (a). There is a tendency to bridging of nests between adjacent rete ridges and there is concentric fibroplasia in the dermis, with patchy lymphocytes and histiocytes (b). Cytologically, there are prominent nucleoli and somewhat irregular nuclear membranes (c). Cells in the dermis show evidence of maturation from superficial to deep (d, e). This lesion presents overlapping features of a 'nevus of special sites', a congenital pattern nevus, and a dysplastic nevus. A descriptive diagnosis may be appropriate, such as 'compound nevus with congenital pattern features, architectural disorder, and cytologic changes of uncertain significance'. A note may be added to suggest that the differential diagnosis includes a 'nevus of special sites' and a dysplastic nevus, and that evaluation of other nevi and melanoma risk factors may be appropriate, especially if there is a family history of melanoma. 
beyond the major dermal component, as is seen in most mucosal melanomas. Moreover, there is no pagetoid spread of single or nested melanocytes into the epidermis, there is no necrosis and usually no ulcer, and importantly there is no mitotic activity in the dermis. ${ }^{52}$

\section{Differential Diagnosis}

The suspicion of nodular melanoma that is falsely aroused by the large nests and the confluence observed at low magnification may appear to be confirmed by the observation at higher power of large cells in the epidermis and upper dermis. However, most lesions show evidence of maturation of the dermal component toward the base of the nevus at the interface of the papillary and reticular dermis. Some of the lesional cells may have eosinophilic nucleoli, but there are no mitoses and there is no necrosis. Further, there is little or no pagetoid extension of atypical melanocytes into the epidermis, there is no 'shoulder' of intraepithelial (junctional or in situ) proliferation at the edge of the dermal component of the lesions, and in the dermis there is no evidence of an expansile, pushing, or infiltrating destructive mass lesion (vertical growth phase melanoma). The distinction from a banal compound nevus is unimportant, because neither lesion has any clinical implication, as long as it is not mistaken for a melanoma. The lentiginous patterns with regular rete ridge elongation that characterize dysplastic nevi are not as a rule seen in genital nevi, and most of these patients do not have dysplastic nevi elsewhere on the skin. We have seen a few undoubted examples of dysplastic nevi on the skin of the labia, but not on the mucous membrane epithelium. Table 3 summarizes differential features that may be helpful in separating nevi of genital skin from vulvar melanoma.

\section{Nevi of the breast}

In a recent study, 101 nevi from the breast area were compared with 97 from elsewhere. Breast nevi exhibited significantly more atypical features than nevi from other sites. In particular, breast nevi tended to show prominent intraepidermal melanocytes, melanocytic atypia, and dermal fibroplasia (Figures 8 and 9). Interestingly, there was no gender difference. ${ }^{59}$ Whether this represents a finding related to site of occurrence of entirely banal nevi (as with genital nevi), or a proclivity for nevi with dysplastic features to favor breast skin is yet to be resolved. There is no doubt that authentic dysplastic nevi may also occur, perhaps preferentially, on the skin of the breast (Figure 3). At present, we report the atypia and generally recommend conservative complete excision for such lesions.

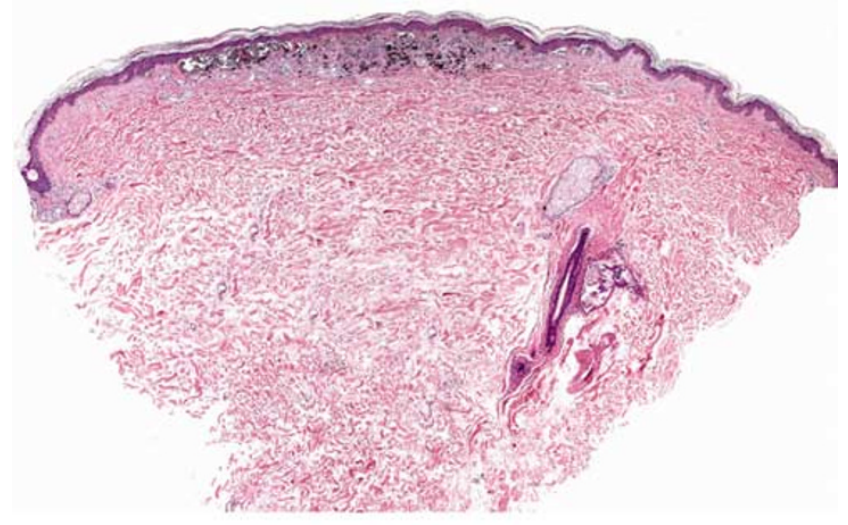

b

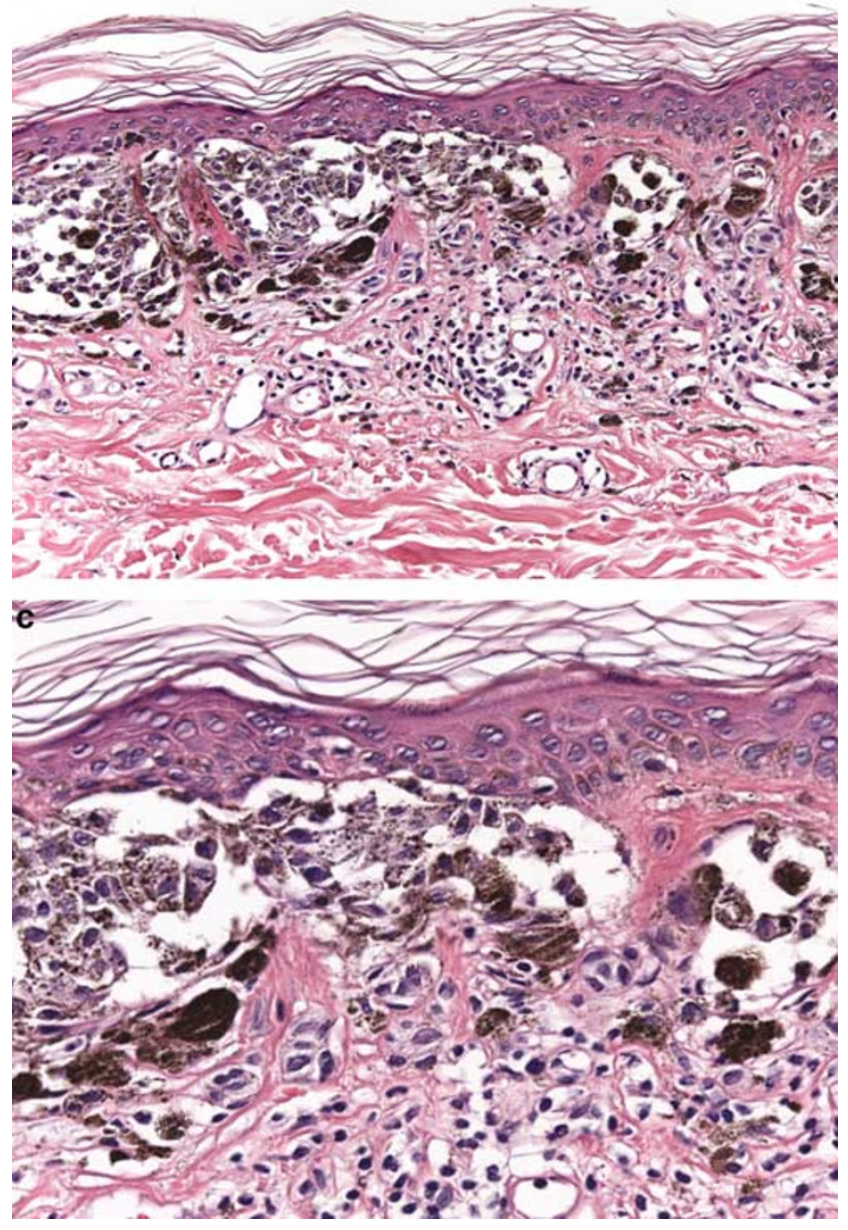

Figure 9 Atypical nevus of the breast in a 65-year-old female patient. This lesion, although small, is quite highly cellular (a). There is a 'nested and dyshesive' pattern with nests that vary in size and shape and tend to become confluent; however, there is no pagetoid proliferation in the epidermis and no continuous basal proliferation (b). Cytologically, there is slight nuclear irregularity and hyperchromatism (c). This lesion presents overlapping features of a dysplastic nevus and a 'nevus of special sites'. A descriptive diagnosis such as 'compound nevus with architectural disorder and cytologic atypia' may be appropriate especially in an individual of this relatively advanced age. If not excised, a recommendation for complete excision may be offered. 
a
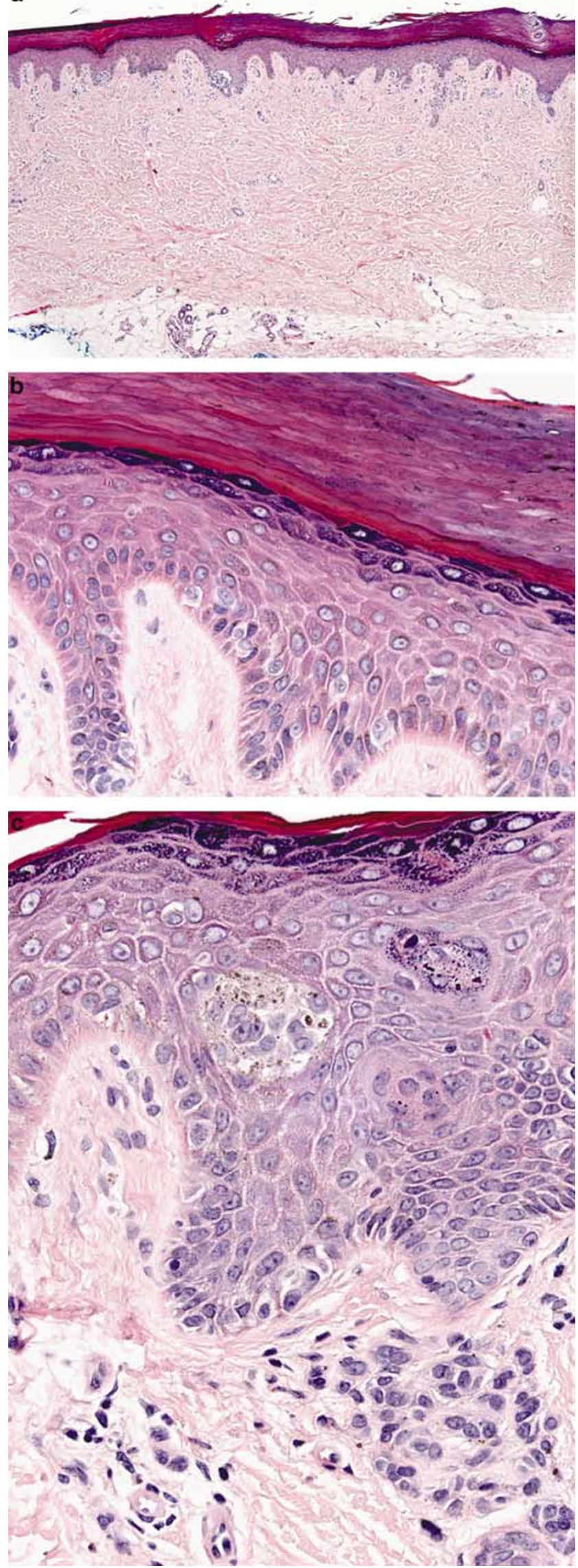

\section{Nevi of acral skin}

Although some older reports suggested that they should be removed to prevent malignant change, acral nevi are present in as many as $4-9 \%$ of the population, ${ }^{60}$ and melanomas are very rare in these sites. Histologically, acral nevi tend to be more cellular than most common nevi, and the nevus cells may be arranged in predominantly lentiginous rather than nested patterns in the epidermis. In addition, occasional low-level pagetoid single cell migration into the stratum spinosum, and even transepidermal elimination of effete pigmented nevus cells within the normally compacted acral stratum granulosum, may be observed (Figure 10). These features may perhaps account for the suspicion in which acral nevi have traditionally been
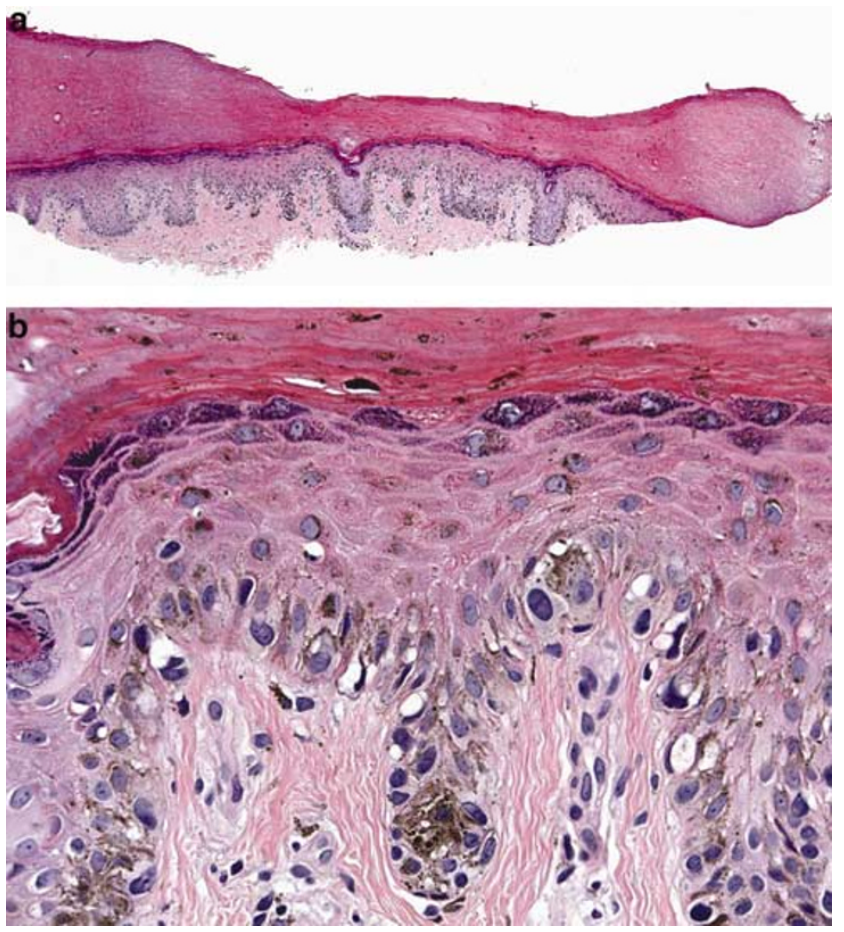

Figure 11 Atypical junctional acral proliferation, melanoma in situ cannot be ruled out. This biopsy, from the sole of the foot in a 48-year-old patient, shows an increased number of single cells along the dermal-epidermal junction. The changes extend to the specimen borders (a). At higher magnification, there is moderate to severe cytologic atypia in the form of nuclear enlargement and hyperchromatism, and there is continuous proliferation along the dermal-epidermal junction (b). Although conceivably part of an acral-lentiginous nevus, these changes could also be from the periphery of a melanoma in situ.

Figure 10 Acral nevus in a 40-year-old patient. There are a few nests and some single cells scattered along the dermal-epidermal junction, with a few clusters of similar cells in the dermis (a). At high magnification, a few of the lesional cells are present above the dermal-epidermal junction, and there are pigments in the stratum corneum (b). A cluster of cells is present in the epidermis, a process akin to 'transepidermal elimination' (c). 
held. However, there is no evidence that these lesions are frequent precursors or risk markers for acral melanomas.

a
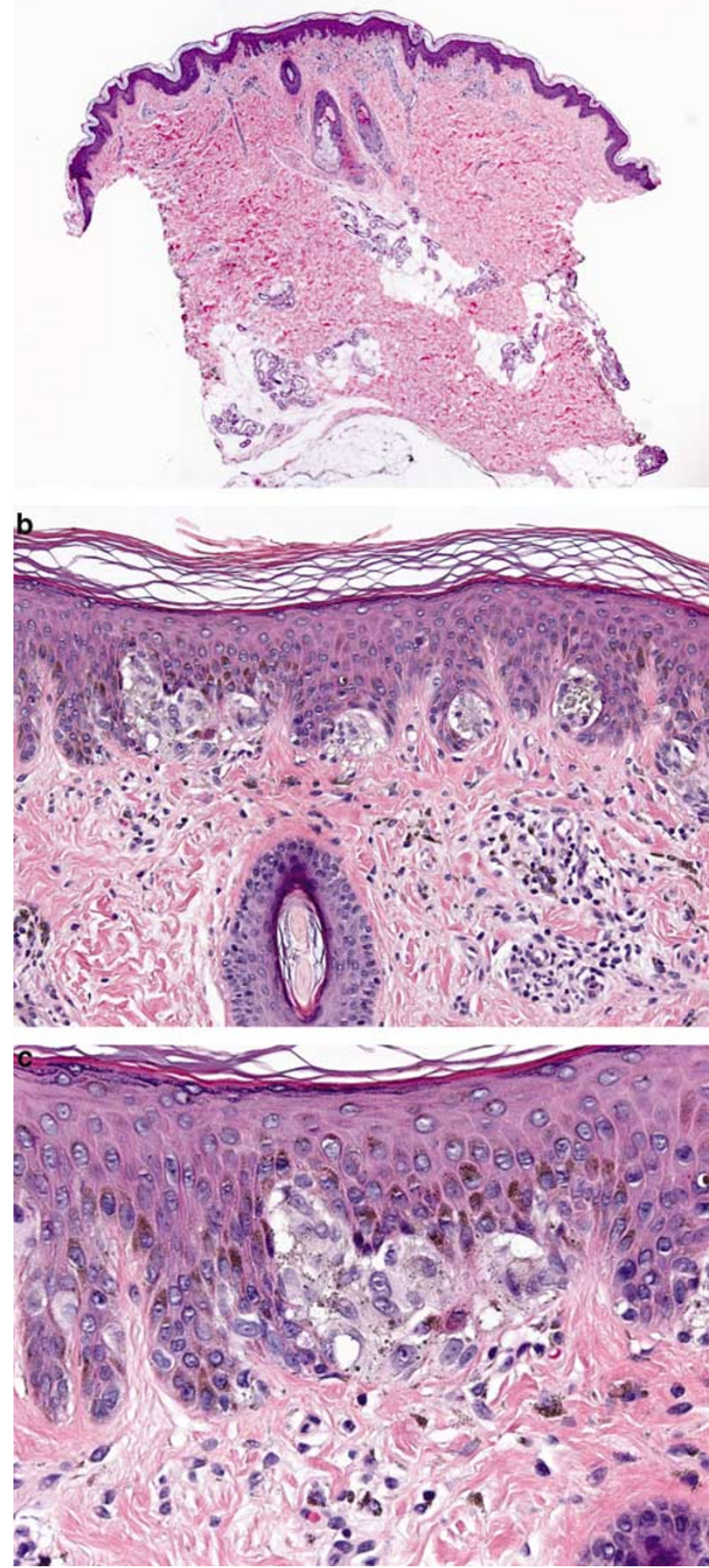

Figure 12 Nevus of the knee. A predominantly junctional melanocytic proliferation measuring $2-3 \mathrm{~mm}$ in diameter on the slide (a). Lesional cells are arranged predominantly in nests near the dermal-epidermal junction, with a suggestion of 'bridging' (b). Lesional cell nuclei are enlarged, with prominent nucleoli (c). This lesion may represent a nevus of special site (flexural). There are some 'dysplastic features', which may be noted in a comment (see legends to Figures 9 and 10).
Acral nevi tend to be circumscribed, light brown lesions that are usually impalpable and flat to side lighting. They are usually stable, and are more often

a
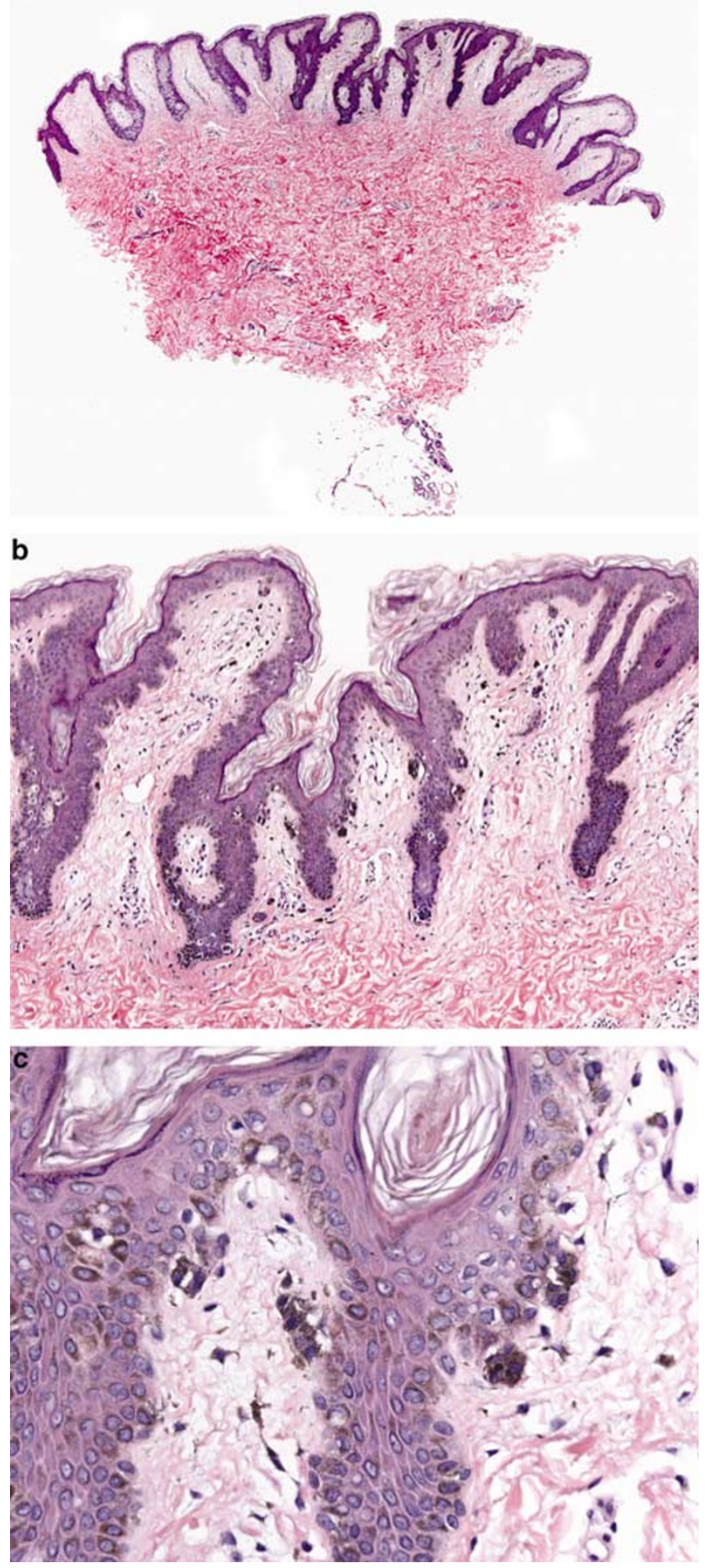

Figure 13 Nevus of the perineum. There is a peculiar pattern of elongated rete ridges at scanning magnification (a). A few nests are arranged mainly near the dermal-epidermal junction, mainly near the sides and tips of these elongated rete (b). Cytologically, there is no atypia (c). This lesion may be signed out as 'junctional nevus', optionally with a comment that it may represent a 'nevus of special sites'. 
junctional than are nevi of the trunk. Like other nevi, they probably may involute and disappear over time. Histologically, lentiginous proliferation of melanocytes is often prominent, with moderate amounts of melanin pigment, or there may be variably sized and shaped nests of melanocytes at the interface. Nevus cells in the dermis, unlike melanoma cells, mature to the lesional base. There

a
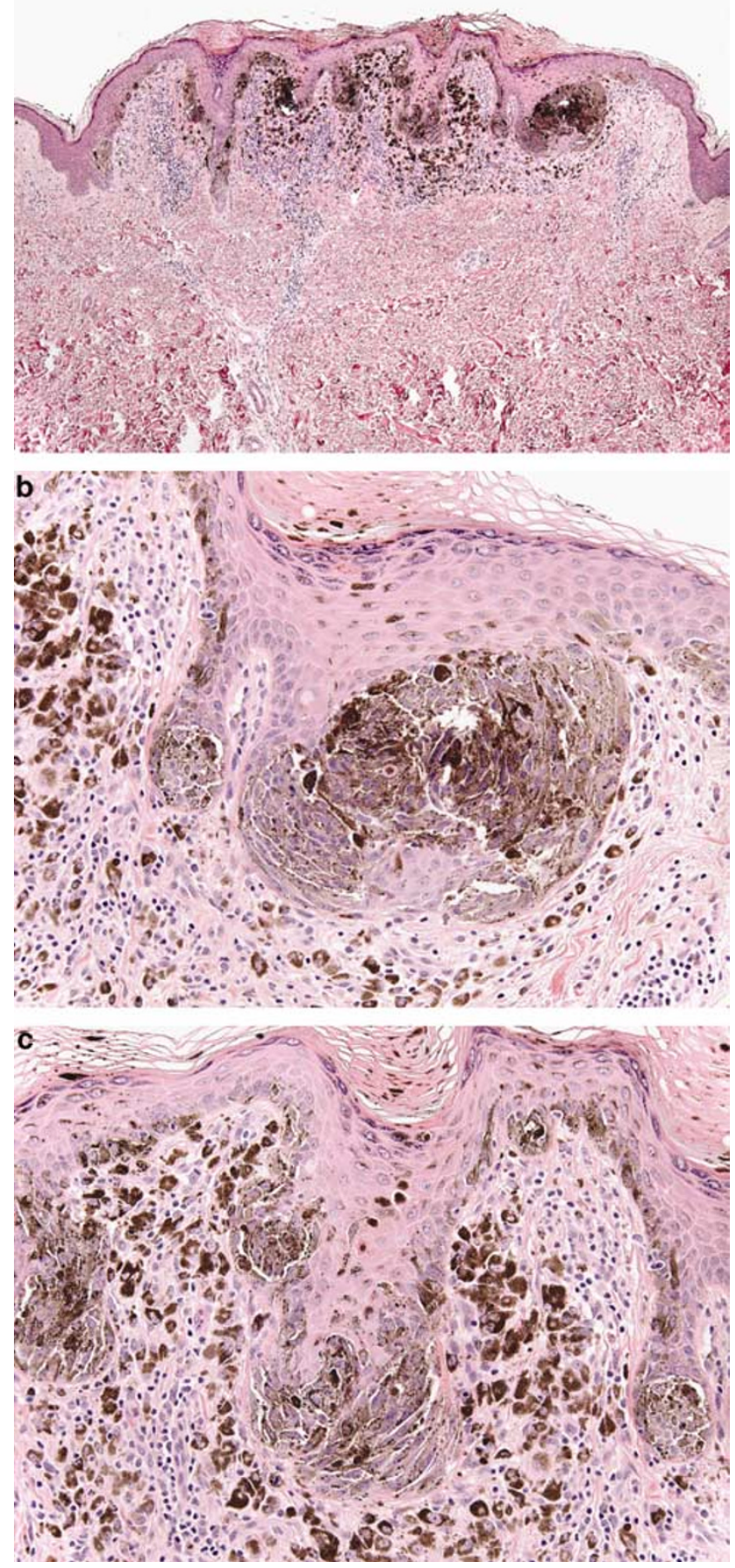

may be patchy lymphocytes and occasional melanophages in the dermis. Some of these features may suggest a dysplastic nevus. However, the rete ridge pattern of keratinocytes does not show the uniform elongation with occasional accentuation of the anastomosing pattern of rete that characterizes dysplastic nevi. If these features are present, and if there is slight to moderate random atypia in a minority junctional epithelioid cell population, the diagnosis of dysplastic nevus can reasonably be made in a lesion of acral skin. Melanoma in situ is the appropriate diagnosis when there is confluent basal proliferation of uniformly atypical melanomas in the epidermis, and invasive melanoma is recognized by the presence of a population of cells in the dermis characterized by uniform atypia, and failure of maturation, with or without mitoses. The diagnosis may be subtle in small early lesions, especially in a partial biopsy which should always be regarded with suspicion (Figure 11). The diagnosis is easier in an advanced lesion when there may be expansile tumorigenic proliferation, dermal mitotic activity, ulceration, necrosis, and vascular, lymphatic invasion, or satellites. Most acral melanomas occur in elderly patients. This form of melanoma is uncommon in all societies, but occurs with about equal frequencies in patients of all ethnic groups and skin types.

\section{Nevi of flexural skin}

Like acral regions, other body sites may also show lentiginous and nested patterns of junctional proliferation that may deviate from ordinary acquired nevi and cause confusion with atypical and dysplastic nevi. One such recently recognized site involves nevi of flexural skin. ${ }^{61}$ Such nevi may show greater variability in the size of junctional nests as well as origin of nests at the edges of rete as well as in inter-rete regions, both features that also occur in dysplastic nevi (Figures 12-14). However, cytologic atypia and associated stromal alterations typical of dysplastic nevi are said to be lacking in nevi of the flexural type. Nevertheless, in the opinion of this author, nevi that meet strict criteria

\footnotetext{
Figure 14 Nevus of the axilla in a 40-year-old woman. This lesion, although small and well circumscribed, is highly cellular and has a brisk lymphohistiocytic inflammatory response (a). Nests vary considerably in size and shape in a "nested and dyshesive' pattern (b). Nuclei are somewhat enlarged with small nucleoli (c). In the absence of continuous proliferation or extensive pagetoid proliferation of uniformly atypical cells, and in the absence of mitotic activity, these changes are not diagnostic of melanoma. The differential diagnosis includes a nevus of special site and a dysplastic nevus. Pigmented spindle cell nevus of Reed might also be considered. Lesion may be signed out descriptively as 'junctional nevus with architectural and cytologic atypia', with a comment referring to the differential diagnosis. A lesion such as this should be completely excised.
} 
for dysplastic nevi in these as in other sites should be designated as such, and patients whose nevi may have some 'dysplastic features' should have their melanoma risk factor status evaluated.

\section{Nevi of the head and neck}

Clinically, nevi of the head and neck tend to be papular lesions that are pigmented compound nevi in childhood and early adult life, and that evolve into flesh-colored dermal nevi as the individuals become older. 'Skin tags', which are common on the neck, may histologically represent simple fibroepithelial polyps or, occasionally, mature dermal nevi. Such lesions may on occasion spontaneously infarct.

In lesions of the face and scalp, it is quite common to observe nevus cells in the lower third of the reticular dermis, a finding that seems to be less common in nevi from other locations and that is considered to be suggestive of a small congenital nevus. More or less specific features of a congenital nevus (present at birth) include a lesional size greater than $1.5 \mathrm{~cm}$, the presence of nevus cells within the epithelium of skin appendages, or a convincing historical confirmation that the lesion was present at birth. ${ }^{62}$ In the absence of these features, these lesions may be regarded as most likely to be acquired nevi (congenital pattern nevi or 'tardive' congenital nevi). Although these lesions are very common in the community, there is an association of these 'congenital pattern nevi' with melanoma, although this is insufficient to warrant wholesale eradication of these lesions with the aim of preventing melanoma ${ }^{63}$ Combined nevi, which in the most common form combine the 'congenital pattern' just described with focal changes of blue nevus, ${ }^{64}$ also appear to be common on the skin of the face. ${ }^{65}$

In a recent study, 101 junctional and compound nevi from the ear were studied. ${ }^{66}$ These lesions were characterized by irregularity of nesting pattern, with nests that varied in size and shape and which were sometimes located between rete ridges. In addition, some of the lesions showed poor circumscription, lateral extension of the junctional component beyond the dermal component, and elongation of rete ridges with bridging between them. About a quarter of them showed uniformly large melanocytes with large vesicular nuclei without prominent nucleoli, and abundant pale, finely granular cytoplasm. These lesions 'did not show a tendency to recur'. In another study of 21 auricular melanocytic nevi (with 32-45 month follow-up), 11 cases measured at least $6 \mathrm{~mm}$ in greatest dimension and six were asymmetric, while 14 cases were ill demarcated. Pagetoid spread was present in 12 cases, and 10 cases showed moderate to severe cytologic atypia, with prominent nucleoli in nine ${ }^{67}$ In reviewing such lesions, the possibility that they are authentic dysplastic nevi should be considered, and it should also be remembered that the ear is one of the most common sites (per unit area) for melanoma especially in males. ${ }^{68}$

\section{References}

1 Clark Jr WH, Reimer RR, Greene $\mathrm{MH}$, et al. Origin of familial melanomas from heritable melanocytic lesions. 'The B-K mole syndrome'. Arch Dermatol 1978;114:732-738.

2 Elder DE, Greene $\mathrm{MH}$, Bondi EE, et al. Acquired melanocytic nevi and melanoma: the dysplastic nevus syndrome. In: Ackerman AB (ed). Pathology of Malignant Melanoma. Masson: New York, 1981, pp 185-216.

3 Elder DE, Green MH, Guerry DIV, et al. The dysplastic nevus syndrome: our definition. Am J Dermatopathol 1982;4:455-460.

4 Sagebiel RW, Banda PW, Schneider JS, et al. Age distribution and histologic patterns of dysplastic nevi. J Am Acad Dermatol 1985;13:975-982.

5 Clemente C, Cochran A, Elder DE, et al. Histopathologic diagnosis of dysplastic nevi. Concordance among pathologists convened by the WHO melanoma programme. Hum Pathol 1991;22:313-319.

6 De Wit PEJ, Van't Hof-Grootenboer B, Ruiter DJ, et al. Validity of the histopathological criteria used for diagnosing dysplastic naevi. An interobserver study by the pathology subgroup of the EORTC Malignant Melanoma Cooperative Group. Eur J Cancer [A] 1993;29A:831-839.

7 Arumi-Uria M, McNutt NS, Finnerty B. Grading of atypia in nevi: correlation with melanoma risk. Mod Pathol 2003;16:764-771.

8 Tucker MA, Fraser MC, Goldstein AM, et al. A natural history of melanomas and dysplastic nevi: an atlas of lesions in melanoma-prone families. Cancer 2002;94: 3192-3209.

9 Friedman RJ, Rigel DS, Kopf AW. Early detection of malignant melanoma: the role of physician examination and self-examination of the skin. CA Cancer J Clin 1985;35:130-151.

10 Abbasi NR, Shaw HM, Rigel DS, et al. Early diagnosis of cutaneous melanoma: revisiting the ABCD criteria. JAMA 2004;292:2771-2776.

11 Gachon J, Beaulieu P, Sei JF, et al. First prospective study of the recognition process of melanoma in dermatological practice. Arch Dermatol 2005;141: 434-438.

12 Rhodes AR, Harrist TJ, Day CL, et al. Dysplastic melanocytic nevi in histologic association with 234 primary cutaneous melanomas. J Am Acad Dermatol 1983;9:563-574.

13 Duray PH, Ernstoff MS. Dysplastic nevus in histologic contiguity with acquired nonfamilial melanoma. Clinicopathologic experience in a 100-bed hospital. Arch Dermatol 1987;123:80-84.

14 Gruber SB, Barnhill RL, Stenn KS, et al. Nevomelanocytic proliferations in association with cutaneous malignant melanoma: a multivariate analysis. J Am Acad Dermatol 1989;21:773-780.

15 Marks R, Dorevitch AP, Mason G. Do all melanomas come from 'moles'? A study of the histological 
association between melanocytic naevi and melanoma. Australas J Dermatol 1990;31:77-80.

16 Sagebiel RW. Melanocytic nevi in histologic association with primary cutaneous melanoma of superficial spreading and nodular types: effect of tumor thickness. J Invest Dermatol 1993;100:322S-325S.

17 Bevona C, Goggins W, Quinn T, et al. Cutaneous melanomas associated with nevi. Arch Dermatol 2003; 139:1620-1624.

18 Halpern AC, Guerry D, Elder DE, et al. Natural history of dysplastic nevi. J Am Acad Dermatol 1993;29:51-57.

19 Halpern AC, Guerry D, Elder DE, et al. A cohort study of melanoma in patients with dysplastic nevi. J Invest Dermatol 1993;100:346S-349S.

20 Kelly JW, Yeatman JM, Regalia G, et al. A high incidence of melanoma found in patients with multiple dysplastic naevi by photographic surveillance. Med J Aust 1997;167:191-194.

21 Wang SQ, Kopf AW, Koenig K, et al. Detection of melanomas in patients followed up with total cutaneous examinations, total cutaneous photography, and dermoscopy. J Am Acad Dermatol 2004;50:15-20.

22 Nordlund JJ, Kirkwood J, Forget BM, et al. Demographic study of clinically atypical (dysplastic) nevi in patients with melanoma and comparison subjects. Cancer Res 1985;45:1855-1861.

23 Swerdlow AJ, English J, MacKie RM, et al. Benign melanocytic naevi as a risk factor for malignant melanoma. Br Med J 1986;292:1555-1559.

24 Holly EA, Kelly JW, Shpall SN, et al. Number of melanocytic nevi as a major risk factor for malignant melanoma. J Am Acad Dermatol 1987;17:459-468.

25 Evans RD, Kopf AW, Lew RA, et al. Risk factors for the development of malignant melanoma-I: Review of case-control studies. J Dermatol Surg Oncol 1988;14:393-408.

26 Augustsson A, Stierner U, Rosdahl I, et al. Common and dysplastic naevi as risk factors for cutaneous malignant melanoma in a Swedish population. Acta Derm Venereol (Stockh) 1991;71:518-524.

27 Halpern AC, Guerry DIV, Elder DE, et al. Dysplastic nevi as risk markers of sporadic (non-familial) melanoma: a case-control study. Arch Dermatol 1991;127:995-999.

28 Tucker MA, Halpern A, Holly EA, et al. Clinically recognized dysplastic nevi. A central risk factor for cutaneous melanoma. JAMA 1997;277:1439-1444.

29 Landi MT, Baccarelli A, Tarone RE, et al. DNA repair, dysplastic nevi, and sunlight sensitivity in the development of cutaneous malignant melanoma. J Natl Cancer Inst 2002;94:94-101.

30 Bliss JM, Ford D, Swerdlow AJ, et al. Risk of cutaneous melanoma associated with pigmentation characteristics and freckling: systematic overview of 10 case-control studies. Int J Cancer 1995;62: 367-376.

31 Ford D, Bliss JM, Swerdlow AJ, et al. Risk of cutaneous melanoma associated with a family history of the disease. The International Melanoma Analysis Group (IMAGE). Int J Cancer 1995;62:377-381.

32 MacKie RM, Freudenberger T, Aitchison TC. Personal risk-factor chart for cutaneous melanoma. Lancet 1989;2:487-490.

33 Rhodes AR, Melski JW, Sober AJ, et al. Increased intraepidermal melanocyte frequency and size in dysplastic melanocytic nevi and cutaneous melanoma. A comparative quantitative study of dysplastic mela- nocytic nevi, superficial spreading melanoma, nevocellular nevi, and solar lentigines. J Invest Dermatol 1983;80:452-459.

34 Ackerman AB, Briggs PL, Bravo F. Dysplastic nevus, compound type vs. Clark's nevus, compound type. Differential diagnosis in dermatopathology III. In: Ackerman AB, Briggs PL, Bravo F (eds). Lea \& Febiger: Philadelphia, 1993, pp 158-161.

35 Nollet DJ. 'Clark's nevus syndrome' [letter]. Am J Dermatopathol 1986;8:367.

36 Steijlen PM, Bergman W, Hermans J, et al. The efficacy of histopathological criteria required for diagnosing dysplastic naevi. Histopathology 1988;12: 289-300.

37 Rhodes AR, Mihm Jr MC, Weinstock MA. Dysplastic melanocytic nevi: a reproducible histologic definition emphasizing cellular morphology. Modern Pathol 1989;2:306-319.

38 Duray PH, DerSimonian R, Barnhill R, et al. An analysis of interobserver recognition of the histopathologic features of dysplastic nevi from a mixed group of nevomelanocytic lesions. J Am Acad Dermatol 1992; 27:741-749.

39 Smoller BR, Egbert BM. Dysplastic nevi can be diagnosed and graded reproducibly: a longitudinal study. J Am Acad Dermatol 1992;27:399-402.

40 Duncan LM, Berwick M, Bruijn JA, et al. Histopathologic recognition and grading of dysplastic melanocytic nevi: an interobserver agreement study. J Invest Dermatol 1993;100:318S-321S.

41 Hartge P, Holly EA, Halpern AC, et al. Recognition and classification of clinically dysplastic nevi from photographs: a study of interobserver variation. Cancer Epidemiol, Biomarkers Prev 1995;4:37-40.

42 Meyer LJ, Piepkorn M, Goldgar DE, et al. Interobserver concordance in discriminating clinical atypia of melanocytic nevi, and correlations with histologic atypia. J Am Acad Dermatol 1996;34:618-625.

43 Weinstock MA, Barnhill RL, Rhodes AR, et al. Reliability of the histopathologic diagnosis of melanocytic dysplasia. The Dysplastic Nevus Panel. Arch Dermatol 1997;133:953-958.

44 Brochez L, Verhaeghe E, Grosshans E, et al. Interobserver variation in the histopathological diagnosis of clinically suspicious pigmented skin lesions. J Pathol 2002;196:459-466.

45 Hastrup N, Clemmensen OJ, Spaun E, et al. Dysplastic naevus: histological criteria and their inter-observer reproducibility. Histopathology 1994;24:503-509.

46 Piepkorn MW, Barnhill RL, Cannon-Albright LA, et al. A multiobserver, population-based analysis of histologic dysplasia in melanocytic nevi. J Am Acad Dermatol 1994;30:707-714.

47 Piepkorn M, Meyer LJ, Goldgar D, et al. The dysplastic melanocytic nevus: a prevalent lesion that correlates poorly with clinical phenotype. J Am Acad Dermatol 1989;20:407-415.

48 Klein LJ, Barr RJ. Histologic atypia in clinically benign nevi. A prospective study. J Am Acad Dermatol 1990; 22:275-282.

49 Hastrup N, Hou-Jensen K. Melanocytic lesions in a private pathology practice. Comparison of histologic features in different tumor types with particular reference to dysplastic nevi. APMIS 1993;101:845-850.

50 Elder DE, Xu X. The approach to the patient with a difficult melanocytic lesion. Pathology 2004;36: $428-434$ 
51 Elder DE, Guerry D, Epstein MN, et al. Invasive malignant melanomas lacking competence for metastasis. Am J Dermatopathol 1984;6(Suppl):55-61.

52 Christensen WN, Friedman KF, Woodruff JD, et al. Histologic characteristics of vulval nevocellular nevi. J Cutan Pathol 1987;14:87-91.

53 Rock B. Pigmented lesions of the vulva. Dermatol Clin 1992;10:361-370.

54 Maize JC, Ackerman AB. Pigmented Lesions of the Skin. Clinicopathologic Correlations. Lea \& Febiger: Philadelphia, 1987.

55 Rock B, Hood AF, Rock JA. Prospective study of vulvar nevi. J Am Acad Dermatol 1990;22:104-106.

56 Friedman RJ, Ackerman AB. Difficulties in the histologic diagnosis of melanocytic nevi on the vulvae of premenopausal women. In: Ackerman AB (ed). Pathology of Malignant Melanoma. Masson: New York, 1981, pp 119-127.

57 Shabrawi-Caelen L, Soyer HP, Schaeppi H, et al. Genital lentigines and melanocytic nevi with superimposed lichen sclerosus: a diagnostic challenge. J Am Acad Dermatol 2004;50:690-694.

58 Carlson JA, Mu XC, Slominski A, et al. Melanocytic proliferations associated with lichen sclerosus. Arch Dermatol 2002;138:77-87.

59 Rongioletti F, Urso C, Batolo D, et al. Melanocytic nevi of the breast: a histologic case-control study. J Cutan Pathol 2004;31:137-140.

60 MacKie RM, English J, Aitchison TC, et al. The number and distribution of benign pigmented moles (melano- cytic nevi) in a healthy British population. Br J Dermatol 1985;113:167-174.

61 Rongioletti F, Ball RA, Marcus R, et al. Histopathological features of flexural melanocytic nevi: a study of 40 cases. J Cutan Pathol 2000;27:215-217.

62 Rhodes AR. Congenital nevomelanocytic nevi. Histologic patterns in the first year of life and evolution during childhood. Arch Dermatol 1986;122:12571262.

63 Betti R, Inselvini E, Vergani R, et al. Small congenital nevi associated with melanoma: case reports and considerations. J Dermatol 2000;27: 583-590.

64 Pulitzer DR, Martin PC, Cohen AP, et al. Histologic classification of the combined nevus: analysis of the variable expression of melanocytic nevi. Am J Surg Pathol 1991;15:1111-1122.

65 McCarthy SW, Scolyer RA. Melanocytic lesions of the face: diagnostic pitfalls. Ann Acad Med Singapore 2004;33:3-14.

66 Lazova R, Lester B, Glusac EJ, et al. The characteristic histopathologic features of nevi on and around the ear. J Cutan Pathol 2005;32:40-44.

67 Saad AG, Patel S, Mutasim DF. Melanocytic nevi of the auricular region: histologic characteristics and diagnostic difficulties. Am J Dermatopathol 2005;27: 111-115.

68 Elder DE. Skin cancer: melanoma and other specific nonmelanoma skin cancers. Cancer 1995;75(Suppl): 245-256. 